\title{
Carative Caring and Cognitive Behavior Therapy on Self Efficacy and Self Care of Covid-19 Patients
}

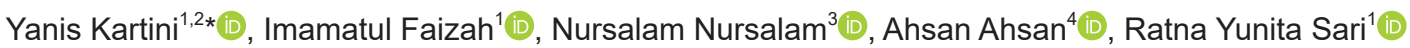 \\ ${ }^{1}$ Departement of Nursing, Nursing and Midwifery Faculty, Universitas Nahdlatul Ulama Surabaya, Surabaya, East Java, \\ Indonesia; ${ }^{2}$ Doctoral Program of Nursing, Faculty of Nursing, Universitas Airlangga, Surabaya, East Java, Indonesia; \\ ${ }^{3}$ Departement of Nursing, Faculty of Nursing, Universitas Airlangga, Surabaya, East Java, Indonesia; ${ }^{4}$ Departement of Nursing, \\ Faculty of Medicine, Universitas Brawijaya, Malang, East Java, Indonesia
}

Edited by: Mirko Zhivko Spirosk Citation: Kartini Y, Faizah I, Nursalam N, Ahsan A, Sar RY. Carative Caring and Cognitive Behavior Therapy on Access Maced J Med Sci. 2022 Jan 24:10(G):86-91. Https: Access Maced J Med Sci. 2022 Jan 24; 10(G):86-91. https:// doi.org/10.3889/oamjms. 2022.7937
Keywords: Carative caring; Cognitive-behavioral therapy; Self-efficacy; Self-care
${ }^{*}$ Correspondence: Yanis Kartini, Departement of Nursing Nursing and Midwifery Faculty, Universitas Nahdlatu Ulama Surabaya, Surabaya, East Java, Indonesia. E-mail: yanis_youarenice@unusa.ac.id Received: $11-$ Nov-2021 Accepted: 19-Jan-2022 Accepted: 19-Jan-2022
Copyright: ๑ 2022 Yanis Kartini, Imamatul Faizah, Nursalam Nursalam, Ahsan Ahsan, Ratna Yunita Sari Funding: The authors disclosed receipt of the following
financial support for the research, authorship, and/or publication of this article: This work was supported by Universitas Nahdlatul Ulama Surabaya [grant number: 161.2.20/UNUSA/Adm-LPPM/III/2021 Competing Interests: The authors have declared that no competing interests.

Open Access: This is an open-access article distribute under terms 4 . International

\begin{abstract}
BACKGROUND: The COVID-19 pandemic in Indonesia is increasing in which affect psychosocial conditions for everyone. COVID-19 patients feel low and afraid because of without family help while being treated in the room so that the patient's self-efficacy and confidence decrease in carrying out patient self-care.

AIM: This study aims to analyze the effect of giving carative caring and cognitive-behavioral therapy on self-efficacy and self-care for COVID-19 patients.

METHODS: The sampling technique used consecutive sampling to determine the sample according to the inclusion and exclusion criteria, with a total sample of 106 respondents who were divided into 53 intervention groups and 53 control group respondents. The instruments used in this study were the caring behaviors assessment tool to measure carative caring. General self-efficacy was used to measure self-efficacy and exercise of self-care agency was used to measure self-care for COVID-19 patients. The data were analyzed using the t-test with a significant level of $p<0.5$.

RESULTS: The results showed that in the group, the difference in the mean self-efficacy before and before the intervention was 10.17, while the difference in the mean self-care before and after the intervention was 10.81. In the control group, the difference in the mean of self-efficacy before and after the intervention was 0.13 , while the difference in the mean of self-care before and after the intervention was 0.02 . Analysis of the data obtained showed that carative caring and cognitive-behavioral therapy influence self-care for COVID-19 patients with a $p=0.00$.

CONCLUSION: Research that aims to analyze the effect of giving carative caring and cognitive behavioral therapy on self-efficacy and self-care for COVID-19 patients proves that carative caring and cognitive-behavioral therapy influence self-efficacy and self-care for COVID-19 patients.
\end{abstract}

\section{Introduction}

The COVID-19 pandemic affects everyone's psychosocial conditions. The number of confirmed cases of COVID-19 is increasing, due to the rapid transmission of COVID-19 through patients' droplets to other people [1]. The government provides a physical distancing policy and the implementing restrictions to community activities during the COVID-19 pandemic to minimize the number of COVID-19 events [2]. People who are confirmed positive for COVID-19 feel tremendous fear and worry in themselves in which they think about whether they can recover, reunite with their families, and carry out their daily activities. Feelings of anxiety and helplessness experienced can reduce the patient's confidence so that it will also affect self-care to maintain their health status [3], [4], [5].

Based on the data in Indonesia, the number of positive cases of COVID-19 on February 9, 2021, was as many as $1,166,079$ people who were confirmed positive for COVID-19 with 963,028 people recovered, and 31,763 people died. In East Java. 118,436 people were confirmed positive for COVID-19 with 104,038 people recovered and 8240 people died. Meanwhile, in the city of Surabaya, 20,352 people were confirmed positive for COVID-19 with 18,796 people recovered and 1303 other people died [6]. The results of a survey conducted by the Association of Indonesian Mental Health Specialists found that $64.3 \%$ of 1522 people felt anxious or depressed after knowing the results of swab tests that they were positive for COVID-19. This is in line with research conducted by Zhang et al. [7] showing that a patient suffering from COVID-19 experienced an increase in the depression of $29.2 \%$ after undergoing self-isolation. The feeling of struggling to be healthy with independent care and having to stay away from family and the stigma in the surrounding community that the community has to stay away from COVID-19 patients create negative feelings in him so that it will affect his psychology, especially in his level of self-confidence and self-care [8], [9]. 
COVID-19 sufferers experience a decrease in self-efficacy due to several factors including long duration of isolation, prejudice in patients regarding being able to re-infect and transmit to other family members, worsening health conditions, isolation saturation factors, waiting time for test results, negative stigma from surrounding communities [10]. COVID-19 patients must be treated in isolation rooms if they have signs and symptoms that require close monitoring by medical personnel. Health monitoring and health services do not only focus on aspects of successful treatment (cure) but also focus on other things. While undergoing isolation in hospitals, COVID-19 patients cannot be waited for by their families who always accompany and assist patients in fulfilling their care [11]. The role of nurses in this condition is very important to apply the concept of carative caring in treating COVID-19 patients so that patients feel safe and comfortable.

Nurses in pandemic conditions are currently required to use level 3 of personal protective equipment that can limit their work movements. However, nurses must still show caring behavior in providing care to patients diagnosed with COVID-19. Caring is a behavior or action taken to provide a sense of physical and emotional security to others sincerely. The behavior displayed by nurses is that nurses are ready to be present to accompany patients, provide comfort, care, health care, protect, provide encouragement, empathy, interest, love, trust, support, touch, and are ready to help and visit clients. This will encourage clients to change their physical, psychological, spiritual, and social aspects for the better [12]. Pajnkihar et al. [11] in Theory of Human Care revealed that ten narrative factors can reflect the caring behavior of a nurse. The ten factors are forming a humanistic-altruistic value system, instilling beliefs and expectations, developing sensitivity for oneself and others, fostering a trusting relationship, helping, increasing and accepting the expression of positive and negative feelings, using systematic problemsolving methods in decision-making, improving the interpersonal teaching and learning process, providing an environment that supports, protects, and or improves mental, socio-cultural, and spiritual, assisting in fulfilling basic human needs, and developing phenomenological existential strength factors.

Nursing interventions that can be done to increase self-efficacy and self-care for COVID-19 patients are cognitive behavior therapy (CBT). The results of the Manuntung 2015 study explained that there was a significant effect in increasing self-efficacy and self-care in hypertensive patients before and after CBT administration with a $p=0.000$. CBT is a modification action to change maladaptive beliefs to solve problems [13]. The CBT approach seeks to focus on thoughts, beliefs, or forms of self-talk about current problems without forgetting past experiences. CBT aims to help a person identify patterns of cognitive, emotional, feeling, and behavior that arise as a thought on a problem [14].
Therefore, the purpose of this study was to analyze the effect of nursing care and cognitivebehavioral therapy on the self-efficacy and self-care of COVID-19 patients. Carative caring is a reflection of nurse caring behavior initiated by Jean Watson which includes humanistic-altruistic, generating trust and hope, developing sensitivity to self and others, helping trust, increasing intuition, and being sensitive to the expression of feelings, using scientific methods to make decisions, improve teaching-learning interpersonal relationships, provide physical, mental, sociocultural, spiritual support, the assistance provided can satisfy human needs, and appreciate the patient's strengths [15]. This intervention is expected to provide the support that COVID-19 patients feel is lacking due to self-isolation. The psychotherapy approach that is used helps clients to think positively and increase self-confidence and perform self-care properly without depending on others, which will have an impact on increasing immunity and health status. The results of this study will be useful for developing treatment interventions for COVID-19 patients.

\section{Methods}

This study used a quasi-experimental research design with the untreated control group design with dependent pre-test and post-test samples. This study involved two groups of subjects, namely the treatment group and the control group. The independent variables in this study were carative caring nurses and CBT. The dependent variables in this study were self-efficacy and self-care.

\section{Sample of research}

The population in this study was all positive COVID-19 patients at the Surabaya Islamic Hospital who met the inclusion and exclusion criteria of the study. Sampling was carried out by using consecutive sampling. The inclusion criteria were patients confirmed positive for COVID-19 with the composmentis and vital signs within normal limits. The exclusion criteria were the patients that had decreased consciousness, communication disorders, and severe psychological disorders. The characteristics of the participants in this study were based on age, gender, education, and occupation. The results of the characteristics of respondents in the study are as follows:

Table 1 shows that the characteristics of the respondents obtained results, that a small proportion in intervention and control group (24.5\% and 20.8\%) in the early old age (46-55). For gender in the intervention group and the control group, most of them are male (50.9\% and $52.8 \%$ ). Based on the educational 
background in the intervention group, almost half of the respondents (45.3\%) were in Senior High School and for the control group, almost half (43.4\%) of the respondents were in Junior High School. For occupation, almost half of respondents in the intervention and control group $(35.8 \%$ and $32.1 \%)$ were civil servants.

Table 1: Characteristics of respondents in the intervention group and control group

\begin{tabular}{|c|c|c|c|c|}
\hline \multirow{2}{*}{ Characteristics } & \multicolumn{2}{|c|}{ Intervention group $(\mathrm{n}=53)$} & \multicolumn{2}{|c|}{ Control group $(n=53$} \\
\hline & $\bar{f}$ & $\%$ & $f$ & $\%$ \\
\hline \multicolumn{5}{|l|}{ Age (years) } \\
\hline Late teens $(17-25)$ & 7 & 13.2 & 4 & 7.5 \\
\hline Early adulthood (26-35) & 9 & 17.0 & 11 & 20.8 \\
\hline Late adulthood (36-45) & 6 & 11.3 & 9 & 17.0 \\
\hline Early old age (46-55) & 13 & 24.5 & 11 & 20.8 \\
\hline Late old age (56-65) & 8 & 15.1 & 10 & 18.9 \\
\hline Old age $(>65)$ & 10 & 18.9 & 8 & 15.1 \\
\hline \multicolumn{5}{|l|}{ Sex } \\
\hline Male & 27 & 50.9 & 28 & 52.8 \\
\hline Female & 26 & 49.1 & 25 & 47.2 \\
\hline \multicolumn{5}{|l|}{ Education } \\
\hline Junior High School & 21 & 39.6 & 23 & 43.4 \\
\hline Senior High School & 24 & 45.3 & 19 & 35.8 \\
\hline University & 8 & 15.1 & 11 & 20.8 \\
\hline \multicolumn{5}{|l|}{ Occupation } \\
\hline Student & 7 & 13.2 & 4 & 7.5 \\
\hline Entrepreneur & 11 & 20.8 & 13 & 24.5 \\
\hline Civil servants & 19 & 35.8 & 17 & 32.1 \\
\hline Private employee & 4 & 7.5 & 4 & 7.5 \\
\hline Does not work & 12 & 22.6 & 15 & 28.3 \\
\hline
\end{tabular}

\section{Instrument and procedures}

The instrument used to measure self-efficacy is the General Self Efficacy (GSE) questionnaire. GSE is a standard measuring tool designed to assess the beliefs held by someone useful in overcoming problems that exist in life. This instrument was developed by Matthias Jerusalem and Ralf Schwarzer. This instrument comprised 10 question items with favorable and unfavorable questions. The reliability coefficient of the self-efficacy scale is $0.82-0.93$. While concurrent validity has been established for the basis of correlation with other tests. An expected positive correlation has been found with measures of self-esteem (0.52) and internal control beliefs (0.49) [16]. Regarding self-care using the Exercise of Self-Care Agency Scale operation by Kearneys and Fleischer with a reliability value of 0.79 , the test-retest correlation was 0.95 and the total item-to-total correlations ranged from 0.41 to 0.74 . All items had validity from 0.54 to 0.91 [17].

This research was conducted in April-June 2021. Researchers first held a zoom meeting regarding the management and benefits of research with medical personnel and prospective respondents, then asked respondents for informed consent and distributed questionnaires via google form assisted by the COVID19 isolation room nurse. The pre-test was carried out one day before the intervention was carried out. The researchers acted as therapists who were assisted by nursing staff as research assistants where the intervention group received carative caring and CBT, which was carried out every day for 2 weeks for $\pm 30 \mathrm{~min}$ during the process of implementing CBT divided into 5 sessions comprising: (1) Initial assessment and diagnosis; (2) Searching for negative emotions, automatic thoughts, and fundamental belief related to the disorder; (3) Developing an intervention plan by providing positive-negative consequences to the client and to "significant people;" (4) Status formulation, therapeutic focus, behavioral intervention follow-up; (5) Relapse prevention. Intervention session was held for 20-30 min for each patient [18]. The control group was not given any intervention, only running the hospital program. The post-test was carried out 1 day after the intervention. This research has been approved by the Ethics Committee of the Surabaya Islamic Hospital with the number 013.EC.KEP.RSIAY.06.21.

\section{Data analysis}

The normality of the data was tested using Kolmogorov Smirnov and the data was normally distributed so that it was continued to conduct data analysis using the paired t-test for data before and after giving carative caring and CBT. The post-test of the intervention group and the control group were analyzed using the independent t-test with the hypothesis of $p<0.05$

\section{Results}

Based on Table 2, the mean of self-efficacy in the intervention group before the action was 7.53 and after the intervention, the mean of self-efficacy was 17.23. For self-care in the intervention group, before the intervention, the average value was 25.02 , and after the intervention, the average value was 35.83 , with the $p=0.000$ which means that there is a significant increase in self-efficacy and self-care before and after being given carative caring and CBT. Meanwhile, in the control group, the mean of self-efficacy in the intervention group before the intervention was 8.04 and after the intervention, the mean of self-efficacy was 8.17 with a $p=0.018$ in self-efficacy. For self-care in the intervention group, before the intervention was taken, a mean of 24.64 was obtained and after the intervention, the mean value was 24.66 with a $p=0.322$ in self-care, which means that there was no significant increase in self-efficacy and self-care in the control group.

Table 2: Self-efficacy and self-care pre and post in the intervention and control group

\begin{tabular}{|c|c|c|c|c|c|c|c|c|c|}
\hline \multirow[t]{2}{*}{ Variable } & \multirow[t]{2}{*}{ Group } & \multicolumn{2}{|l|}{ Pre } & \multicolumn{2}{|l|}{ Post } & \multirow[t]{2}{*}{$95 \% \mathrm{Cl}$} & \multirow[t]{2}{*}{$t$} & \multirow[t]{2}{*}{$\mathrm{n}$} & \multirow[t]{2}{*}{$p$-value } \\
\hline & & Mean & SD & Mean & SD & & & & \\
\hline & Inter & 7.53 & 2.26 & 7.23 & 2.33 & $(-10$ & -28.78 & 53 & 000 \\
\hline efficacy & Control & 8.04 & 2.08 & 8.17 & 2.11 & $(-0.2$ & -2.44 & 53 & 0.018 \\
\hline Selt & Intervention & 25.02 & 1.92 & 35.83 & 3.51 & $(-11.88)-(-9.74)$ & -20.21 & 53 & 0.000 \\
\hline care & Control & 24.64 & 2.01 & 24.66 & 1.99 & $(-0.06$ & -1.00 & 53 & 0.322 \\
\hline
\end{tabular}

Table 3 shows that from the results of data analysis, the $p=0.000$ on self-efficacy and self-care. After conducting the intervention in the intervention group, the mean difference of self-efficacy, before 
Table 3: The value of the difference in self-efficacy and self-care pre and post in the intervention group and the control group

\begin{tabular}{|c|c|c|c|c|c|c|c|c|c|c|}
\hline \multirow[t]{2}{*}{ Variable } & \multirow[t]{2}{*}{ Group } & \multirow[t]{2}{*}{ Mean } & \multirow[t]{2}{*}{ SD } & \multirow[t]{2}{*}{ SE } & \multirow[t]{2}{*}{$\mathrm{n}$} & \multirow[t]{2}{*}{ Mean difference } & \multirow[t]{2}{*}{$\mathrm{t}$} & \multirow[t]{2}{*}{$95 \% \mathrm{Cl}$ minimal-maximal } & \multicolumn{2}{|c|}{$p$-value } \\
\hline & & & & & & & & & Pre & Post \\
\hline \multirow[t]{2}{*}{ Self Efficacy } & Intervention & 17.23 & 2.33 & 0.32 & 53 & 10.17 & \multirow[t]{2}{*}{20.96} & \multirow[t]{2}{*}{$(8.20-9.91)$} & \multirow[t]{2}{*}{0.875} & \multirow[t]{2}{*}{0.000} \\
\hline & Control & 8.17 & 2.11 & 0.29 & 53 & 0.13 & & & & \\
\hline \multirow[t]{2}{*}{ Self Care } & Intervention & 35.83 & 3.51 & 0.48 & 53 & 10.81 & \multirow[t]{2}{*}{20.12} & \multirow[t]{2}{*}{$(10.07)-(12.27)$} & \multirow[t]{2}{*}{0.001} & \multirow[t]{2}{*}{0.000} \\
\hline & Control & 24.66 & 1.99 & 0.27 & 53 & 0.02 & & & & \\
\hline
\end{tabular}

and after the intervention was 10.17 , while the mean difference of self-care, before and after the intervention was 10.81 in the control group. Besides, the mean difference of self-care, before and after the intervention was 0.13 , while the mean difference of self-care before and after the intervention was 0.02 .

\section{Discussion}

Clinical manifestations of COVID-19 patients can be asymptomatic (without symptoms) or symptomatic, which include mild symptoms such as high fever, cough, flu, and sore throat, severe symptoms such as shortness of breath, pneumonia, severe pneumonia, sepsis, and illness, and more severe ones such as Middle East Respiratory Syndrome and Severe Acute Respiratory Syndrome [19]. Table 1 shows that a small proportion of the intervention and control groups (24.5\% and $20.8 \%$ ) were in advanced adulthood (46-55). In previous studies linking the age factor with mortality, it showed that the age group $>50$ years infected with COVID-19 had a higher risk of death compared to the age group $<50$ years [20]. There is a relationship between age and the level of natural immunity, where elderly patients are more easily infected with COVID-19 due to a decrease in natural immunity in the body [21]. Besides, elderly patients experience several degenerative diseases that require the consumption of several types of drugs simultaneously to treat comorbidities that result in decreased organ function [22].

The results of the study in Table 1 also showed that the intervention group and control group were mostly male $(50.9 \%$ and $52.8 \%)$. Based on a metaanalysis study linking gender with the risk of COVID-19 infection, it is known that men are $28 \%$ more at risk of infection than women. Comparable to the relationship between sex and mortality which shows that men are $1.86 \%$ more at risk of dying than women [20]. Men have higher ACE2 expression, this is related to the sex hormone that causes men to be more at risk of contracting COVID-19. ACE2 expression is encoded by a gene found on the $X$ chromosome in which a female is heterozygous while a male is homozygous, so it has the potential to increase ACE2 expression. COVID-19 infection and some other clinical symptoms can be neutralized because women carry a heterozygous $X$ label called sexual dimorphism [23].
The results of the study in Table 3 showed that in the intervention group there was an increase in the value of self-efficacy of 9.7. The increase in selfefficacy in the intervention group occurred because of the provision of carative caring and CBT interventions from nurses. This is in line with the research of [24] which examined the resilience of patients recovering from COVID-19 in terms of self-efficacy in which the three subjects received both external motivations, including from medical personnel or family, and internal motivation within the patient so that the subject always think positive and be more resilient. External motivation can be given by nurses through carative caring and CBT. The carative caring theory explains that one of them is to develop self-sensitivity towards oneself and others [11]. Caring behavior includes providing a caring attitude to clients such as attention. Caring is peoplecentered, respecting dignity and humanity. Caring commits to prevent something bad from happening, to give attention and concern, to respect other people and human life. In addition to carative caring, nurses also provide CBT which aims to increase the patient's self-efficacy.

Research by Li et al. [14] regarding the effects of CBT on depression, anxiety, and stress in patients with COVID-19 showed that after the intervention, more participants in the intervention group did not have symptoms of depression or anxiety than the control group with a $p=0.005$. CBT is a psychotherapeutic approach that is used to treat dysfunctional emotions, maladaptive behaviors, and cognitive processes through goal-oriented procedures with systematic procedures to increase patients' self-efficacy.

Individuals with good self-efficacy will have strong self-control abilities in dealing with threats, have fewer problems, and are easier to recover quickly [25]. A person's behavior is influenced by the individual's perception of three things, namely the perception of the level of risk, the expectation that the behavior will reduce risk, and the expectation that they can make behavioral changes [26]. These three perceptions together will affect behavioral intentions and efforts to make behavior changes and maintain new behaviors that have been carried out. Good self-efficacy will make individuals feel able to carry out self-care behavior so that they can reduce further complications.

The results of the study in Table 3 show an increase in self-care in the intervention group of 10.78 . Factors that affect self-care include respondents' characteristics, knowledge, attitudes, beliefs, values, and traditions [27]. Giving carative caring is an activity 
carried out by nurses in terms of helping patients to meet their needs and providing patients with education so that patients can carry out activities independently. Besides, the CBT approach tries to focus on thoughts, beliefs, or forms of self-talk about current problems without forgetting past experiences. CBT aims to help a person to identify patterns of cognitive, emotional, feeling, and behavior that arise as a thought on a problem [15].

\section{Conclusions}

This study has found that there is an effect of carative caring and CBT on self-efficacy and selfcare for COVID-19 patients. Patients who received carative caring and $\mathrm{CBT}$ interventions experienced an increase in self-efficacy and self-care. The contribution of this research is to increase self-motivation in COVID-19 patients so that patients can meet their daily needs independently. The results of this study can be used as a reference for nurses in providing nursing interventions for COVID-19 patients.

\section{Acknowledgments}

The authors would like to thank all COVID-19 patients at the Surabaya Islamic Hospital who were willing to be respondents and medical personnel in the isolation room of the Surabaya Islamic Hospital who have collaborated with researchers during data collection and the research process. Acknowledgments are expressed to Universitas Nahdlatul Ulama Surabaya in terms of research funding.

\section{Author Contribution}

Yanis Kartini: Conceptualization, methodology, writing-original draft, and supervision. Imamatul Faizah: Formal analysis, Writing-review and editing. Nursalam: Investigation, resources, and data duration. Ahsan: Visualization, project administration and funding acquisition. Ratna Yunita Sari: Software, and validation.

\section{References}

1. Ouassou H, Kharchoufa L, Bouhrim M, Daoudi NE, Imtara H, Bencheikh $\mathrm{N}$, et al. The pathogenesis of Coronavirus disease
2019 (COVID-19): Evaluation and prevention. J Immunol Res. 2020;2020:1357983. https://doi.org/10.1155/2020/1357983 PMid:3267111

2. Pujaningsih NN, Sucitawathi IG. Implementation of The Policy of Limiting The Activities of The COVID-19 Outbreak in The City of Denpasar. J Moderat. 2020;6(3):458-70.

3. Alessi J, de Oliveira GB, Franco DW, do Amaral BB, Becker AS Knijnik CP, Kobe GL, et al. Mental health in the era of COVID-19: Prevalence of psychiatric disorders in a cohort of patients with Type 1 and Type 2 diabetes during the social distancing. Diabetol Metab Syndr. 2020;12:76. https://doi.org/10.1186/ s13098-020-00584-6

PMid:32879637

4. Rajkumar RP. COVID-19 and mental health: A review of the existing literature. Asian J Psychiatr. 2020;52:102066. https:// doi.org/10.1016/j.ajp.2020.102066

PMid:32302935

5. Lee J, Kim E, Wachholtz A. The effect of perceived stress on life satisfaction: The mediating effect of self-efficacy. Chongsonyonhak Yongu. 2016;23(10):29-47. https://doi. org/10.21509/KJYS.2016.10.23.10.29 PMid:27996059

6. Kementerian KR. Info Terkini COVID-19, 26 Januari 2021 Jakarta, Indonesia: Kementerian Kesehatan Republik Indonesia; 2021.

7. Zhang J, Lu H, Zeng H, Zhang S, Du Q, Jiang T, Du B. The differential psychological distress of populations affected by the COVID-19 pandemic. Brain Behav Immun. 2020;87:49-50. https://doi.org/10.1016/j.bbi.2020.04.031

PMid:32304883

8. Liang Z, Luo H, Liu C. The concept of subjective well-being: Its origins an application in tourism research: A critical review with reference to China. Tour Critiques. 2021;2(1):2-19.

9. Norcross JC, Phillips CM. Psychologist self-care during the pandemic: Now more than ever. J Health Serv Psychol. 2020;2:1-5. https://doi.org/10.1007/s42843-020-00010-5 PMid:32363350

10. Yıldırım M, Güler A. COVID-19 severity, self-efficacy, knowledge, preventive behaviors, and mental health in Turkey. Death Stud. 2020;7(16):1-8. https://doi.org/10.1080/07481187.2020.17934 34 PMid:32673183

11. Pajnkihar M, Stiglic G, Vrbnjak D. The concept of Watson's carative factors in nursing and their (dis)harmony with patient satisfaction. PeerJ. 2017;5:e2940. https://doi.org/10.7717/ peerj. 2940 PMid:28194310

12. Amidos J. Caring Concept in Nursing: Jean Watson Theory Opproach; 2020. https://doi.org/10.31219/osf.io/7d4kt

13. Fenn $K$, Byrne $M$. The key principles of cognitive behavioural therapy. Vol. 6. In: InnovAiT: Education and Inspiration for General Practice; 2013. p. 579-85. https://doi. org/10.1177/1755738012471029

14. Li J, Li X, Jiang J, Xu X, Wu J, Xu Y, et al. The effect of cognitive behavioral therapy on depression, anxiety, and stress in patients with COVID-19: A randomized controlled trial. Front Psychiatry. 2020;11:580827. https://doi.org/10.3389/fpsyt.2020.580827 PMid:33192723

15. Karimi Z, Fereidouni Z, Behnammoghadam M, Alimohammadi N Mousavizadeh A, Salehi T, et al. The lived experience of nurses caring for patients with COVID-19 in Iran: A phenomenological study. Risk Manag Healthc Policy. 2020;13:1271-8. https://doi. org/10.2147/RMHP.S258785

PMid:32904130 
16. Schwarzer R. The General Self-Efficacy Scale (GSE); 2021.

17. Guo L, Zauszniewski JA, Ding X, Zhang L, Gao H, Guo Q, et al. The appraisal of self-care agency scale-revised (ASAS-R): Reliability and validity among older Chinese people. West J Nurs Res. 2017;39(11):1459-76. https://doi. org/10.1177/0193945916672821

\section{PMid:27703077}

18. Waller G, Pugh M, Mulkens S, Moore E, Mountford WA, Carter J, et al. Cognitive-behavioral therapy in the time of coronavirus: Clinician tips for working with eating disorders via telehealth when face-to-face meetings are not possible. Int J Eat Disord. 2020;53(7):1132-41. https://doi.org/10.1002/eat.23289

19. WangC,HorbyPW,HaydenFG,GaoGF.Anovelcoronavirusoutbreak of global health concern. Lancet. 2020;395(10223):470-473. https://doi.org/10.1016/S0140-6736(20)30185-9

PMid:31986257

20. Biswas M, Rahaman S, Biswas TK, Haque Z, Ibrahim B. Association of sex, age, and comorbidities with mortality in COVID-19 patients: A systematic review and metaanalysis. Intervirology. 2020;6205:1-12. https://doi. org/10.1159/000512592

PMid:3329690

21. Luan J, Lu Y, Jin X, Zhang L. Spike protein recognition of mammalian ACE2 predicts the host range and an optimized ACE2 for SARS-CoV-2 infection. Biochem Biophys Res Commun. 2020;526(1):165-169. https://doi.org/10.1016/j. bbrc.2020.03.047

PMid:32201080
22. Huang C, Wang $\mathrm{Y}$, Li X, Ren L, Zhao J, Hu Y, et al. Clinical features of patients infected with 2019 novel Coronavirus in Wuhan, China. Lancet. 2020;395(10223):497-506. https://doi. org/10.1016/S0140-6736(20)30183-5

PMid:31986264

23. Gemmati D, Bramanti B, Serino ML, Secchiero P, Zauli G, Tisato V. COVID-19 and individual genetic susceptibility/ receptivity: Role of ACE1/ACE2 genes, immunity, inflammation and coagulation. Might the double X-chromosome in females be protective against SARS-CoV-2 compared to the single X-chromosome in males? Int J Mol Sci. 2020;21(10):3474. https://doi.org/10.3390/ijms21103474

PMid:32423094

24. Diponegoro AM, Khasanah IN, Salma N, Perceka MZ, Murti VS, Vallyzsanta $\mathrm{Y}$, et al. The resilience of recovered COVID-19 patients; 2020. p. 386-92. https://doi.org/10.18502/ kss.v4i15.8227

25. Manuntung A. The Effect of Cognitive Behavioral Therapy (CBT) on Self-efficacy and Self-care Behavior in Hypertenive Patients. Mutiara Med. 2015;15(1):40-51.

26. Xiong $\mathrm{H}, \mathrm{Yi} \mathrm{S}$, Lin $\mathrm{Y}$. The psychological status and self-efficacy of nurses during COVID-19 outbreak: A cross-sectional survey. Inquiry. 2020;57:46958020957114. Https://doi. org/10.1177/0046958020957114 PMid:32900271

27. Mehraeen E, Hayati B, Saeidi S, Heydari M. Self-care instructions for people not requiring hospitalization for Coronavirus disease 2019 (COVID-19). Arch Clin Infect Dis. 2020;15(11):e102978. https://doi.org/10.5812/archcid.102978 